\title{
LA CIENCIA Y LA CONDICIÓN HUMANA
}

Sandra N. C. CAPONI ${ }^{1}$

- RESUMEN: Este escrito se propone tematizar los vínculos existentes entre la investigación científica y la reflexión ética. Con la finalidad de abordar esa cuestión nos proponemos aquí retrotraernos hasta el pensamiento griego, y detenernos en ese momento preciso en que algo semejante a la "verdad científica" emerge por primera vez, pasando así a formar parte de lo "decible". Nos referimos a ese instante inaugural en el que surgieron, casi al mismo tiempo, la reflexión histórica, el saber médico y la investigación jurídica. Intentaremos mostrar que, en ese contexto, la preocupación por la verdad lejos de ser ajena a la reflexión ética fue considerada como el recurso mas eficaz, aquel que mejor podía contribuir, con el intento de alcanzar una vida digna de ser vivida.

- PALABRAS-CLAVE: Verdad; ética; saber médico; discurso jurídico; investigación histórica.

\section{La ciencia en el ámbito del obrar}

Situar a la ciencia hoy como una realidad institucional nos lleva, casi necesariamente, a preguntarnos por los efectos de la racionalidad científica sobre nuestro entorno cotidiano. De modo inevitable parecemos obligados a recordar los horrores asociados a recientes experiencias nucleares sobre seres humanos, y nos vemos impulsados a acordar con la denuncia que, ya hace tiempo, Adorno e Horkheimer levantaron contra esa razón ilustrada que, con un mismo gesto, sojuzga y emancipa, libera y manipula a estos habitantes del presente que somos nosotros mismos.

Es así que cuando hoy hablamos de ciencia parece imperativo atender a ese otro ámbito que es el de la reflexión ética, intentar especificar cual es el tipo de vínculo que debería establecerse entre la investigación científica y el ámbito de la ética. A fin de tematizar esa cuestión nos proponemos aquí, retrotraernos hasta el pensamiento griego, detenernos en ese momento preciso en que algo semejante a la "verdad" científica emerge por vez primera y pasa así a formar parte del ámbito de lo decible.

1 Doutora em Lógica e Filosofia das Ciências - Unicamp. Professora do Centro de Ciências da Saúde - PEN-UFSC - 88040-900 - Florianópolis - SC. 
Ese momento de emergencia marca el fin de una antigua forma de enunciar la verdad que se correspondía con un "juego de prueba", y, al mismo tiempo, señala el inicio de ese modo de producir la verdad que el pensamiento occidental ha heredado. Ella será pensada desde entonces como algo que es más próximo a la comprobación y a la indagación que a los rituales mágicos o a los juegos de prueba.

En La verdad y las formas juńdicas, Michel Foucault (1983) especifica esa mutación epistémica por referencia a una tragedia que, según afirma, es el primer testimonio de las prácticas judiciales griegas. Se trata de la tragedia de Edipo, donde desde el inicio se pone en juego la pretensión de descubrir cierta verdad (quién mató a Layo?) a través de nuevas técnicas de investigación que nada tienen que ver con las formas de pesquisa propias de la época clásica.

Nos interesa mostrar aquí que ese momento histórico en el que emerge un nuevo mecanismo de producción de la verdad, excede el ámbito del discurso y de la investigación jurídica. Pretendemos mostrar que un movimiento semejante ocurrió en otros ámbitos del saber que modificaron, por entonces, sus estrategias de producción de la verdad de un modo análogo. Nos referimos a ese instante inaugural en que emergieron la reflexión histórica y el saber médico. En ambos casos se edifica un nuevo modo de reflexión sobre nuestras conductas y sobre nuestros cuerpos cuyas verdades no resultarán de juegos de prueba, sino de esos procedimientos casi jurídicos que son la comprobación, el recurso a testigos y la indagación.

Antes de detenernos a analizar esos mecanismos que el discurso jurídico, histórico y médico "inventaron" para producir sus propias verdades, deberemos recordar que es ese también el instante en que surge una preocupación ética por modelar los cuerpos y las almas a fin de producir a la existencia como "estética". Surge entonces una preocupación por la "buena vida" que parece ser indisociable de la propia investigación científica. Solo si recordamos que la verdad no es para el pensamiento griego mas que otro nombre para designar el bien y la belleza, podremos entender esta vuelta al pensamiento griego. Es que, por entonces, la investigación científica, la preocupación por la verdad, no es más que un recurso eficaz, aquel que mejor puede contribuir a la producción de una existencia digna.

\section{La invención del saber}

Veamos ahora cómo es que esos nuevos mecanismos de producción del saber se diferencian de los rituales arcaicos. Un buen testimonio de lo que era considerado hasta entonces como investigación judicial puede ser encontrado en La Ilíada. Se trata de un litigio que se establece entre Antíloco y Menelao por una carrera de carros. Allí, aunque se trata de un circuito que exige pasar ante un testigo, un responsable que está allí para ver, en el momento de esclarecer la verdad sobre el triunfador Homero, extrañamente, no apela a ese observador, no cita su testimonio, sino que pre- 
fiere recurrir a un juego de prueba. Se trata de un desafío que no es más que un juramento de inocencia. Antíloco renuncia a la prueba, evidenciando así su culpabilidad por el temor que los dioses inspiran. Lo cierto es que hay allí una figura ausente, no es el testigo quien conduce a la verdad sino un desafío, una prueba que nos remite en última instancia a una voluntad divina capaz de punir los falsos juramentos.

La tragedia de Edipo parece inscribirse en otro orden del saber. Aparece allí un nuevo mecanismo para establecer la verdad que responde a algo que bien podría ser descripto como "ley de las mitades". En efecto la verdad nunca se dice enteramente sino hasta el fin de la tragedia. La investigación jurídica consistirá, en consecuencia, en intentar recomponer en un orden lógico aquello que se conoce solo de un modo parcial. La sentencia de Apolo "si quieres que acabe la peste es preciso acabar con la maldición" o la sentencia de Tiresias "prometiste desterrar al asesino-ordeno que cumplas y te destierres", solo enuncian la verdad bajo una forma profética, prescriptiva, bajo la forma del oráculo. Pero, ahora esa verdad ya no basta, no es más que una media verdad a la que le falta la dimensión de la actualidad. Esas sentencias hablan en imperativo, pero presuponen una verdad que precisa ser probada. Una verdad que ya había sido enunciada por el oráculo y que había llevado a Edipo a abandonar la corte de Corinto para evitar el parricidio y el incesto al que parecía estar predestinado.

Ya no bastan los juegos de prueba, las promesas, los juramentos o las maldiciones, ahora se hace preciso investigar, determinar fehacientemente sí la verdad profética se corresponde con aquello que parece haber ocurrido efectivamente. Aquí hará falta recurrir a esa vieja figura del que "está allí para ver", a esa figura del "testigo" que parecía estar al margen de los juegos de verdad. El primer testimonio lo dará Yocasta al desestimar al oráculo y recordar las condiciones en que murió Layo. Ese enunciado acoplado con el recuerdo de Edipo dará la verdad del asesinato de Layo. Sin embargo, hasta que no se pruebe que Edipo es hijo de Layo la predicción no se verifica. Será allí que dos nuevos testimonios deberán juntarse para poder producir esa temida verdad. Uno es el del mensajero de Corinto que anuncia la muerte de Polibio y dice a Edipo que él no era su padre, otro es el pastor de Citerón que dice haber dado al mensajero un hijo de Layo y Yocasta. El círculo se ha cerrado por el acoplamiento de la profecía y el testimonio. La verdad emerge del encuentro entre dos series una que es prescriptiva y prospectiva y otra que es descriptiva y retrospectiva.

A esa mirada mágica que sabía prever lo que ocurriría sería preciso contraponer otra mirada, la de los ojos humanos, la de los testigos. La verdad que resulta de ese encuentro no nos habla solo de la imputabilidad jurídica de Edipo sino también de su imputabilidad moral. Sus actos no se consideran como ya establecidos de antemano por el poder del destino sino hasta el final. "Solamente en Edipo en Colona veremos a un Edipo ciego y miserable que gime a lo largo de la obra diciendo: 'yo nada podía hacer, los dioses me cogieron una trampa que no había previsto'" (Foucault, 1983, p.50). Por el contrario, en "Edipo Rey" no se alegará inocencia o temor a la ley, pues la figura del tirano parece despreciar, como lo reprocha el coro del pueblo, 
la diqué, la justicia: "Poco me importa que sea o no justo, igual debes obedecer". Sabemos que para los griegos la justicia no es solo una virtud entre otras, sino que se trata de la virtud por excelencia, y que su desconocimiento implica debilidad e infelicidad.

Antes decíamos que el ámbito de la ética no es independiente, para los griegos, del modo de producción de la verdad. Como intentamos mostrar, la tragedia resulta del modo en que Edipo se ve enfrentado, poco a poco, con la verdad. Si hasta ahora era su voluntad quién determinaba la ley, si hasta ahora su saber solitario había bastado para descifrar los enigmas de la Divina Cantora, ahora esta posición privilegiada será revertida: para determinar la verdad deberá oír otras voces, deberá atender a otras miradas que no son las suyas. Si se quiere acceder a la verdad será preciso reconocer la virtud de la justicia, será preciso oír aquello que los dioses profetizan pero también aquello que los ojos humanos recuerdan. Se deberá renunciar al saber autocrático del tirano - que por si mismo cree saberlo todo- para poder desdivinizar el saber.

Si atendemos ahora al ámbito de la história, si nos preguntamos por sus condiciones de emergencia, deberemos situarnos en el siglo $\mathrm{V}$ a.C., pues hasta entonces, como afirma Collingwood (1989, p.22) de modo casi nietzscheano, "la historia no existía". En efecto, es a partir de Heródoto y Tucídides que la historia deja de ser leyenda, historia que contar, para pasar a ser investigación o inquisición (tal como queda significado con la palabra griega - "Historia"). Lo cierto es que para Collingwood la historia es el efecto de una invención, de una fabricación tan renovadora como lo eran, para Nietzsche, la invención del arte o del conocimiento.

Es así que aún cuando sus contemporáneos no la considerasen, en sentido estricto, científica, creemos con Collingwood, que la historia en cuanto ciencia aparece como una invención griega del siglo $\mathrm{V}$ que puede ser claramente diferenciada de los relatos arcaicos; como por ejemplo de los relatos homéricos considerados por ese autor como "cuasi-históricos". Aún cuando la narración nos remite en este último caso al pasado, no se trata de responder a preguntas sino de relatar afirmaciones sobre verdades que el escritor ya conoce de antemano. Los actos que entran en juego no son en sentido estricto actos humanos sino actos divinos, o bien acciones en las que los humanos intervienen a modo de instrumento o de pacientes de otras voluntades, las divinas, que rigen su conducta.

La invención de la historia instaura un nuevo modo de producir la verdad que puede ser pensado por analogía a los nuevos procedimientos judiciales que por entonces se estaban gestando. Es entonces que la historia deja de ser leyenda para pasar a ser investigación. De lo que se trata ahora es de poder "dar respuestas bien definidas acerca de asuntos que confesadamente se ignoran" (Collingwood, 1989, p.26). La memoria ha dejado lugar a la investigación y la polémica que pasan ahora a formar parte del conocimiento. Aquello que se supone o que se imagina, deberá pasar a formar parte de un diálogo entre humanos donde la figura del testigo ocupará un lugar de 
privilegio. Esto no significa que el testigo ocupe ese lugar del saber que antes era patrimonio de los dioses; el que está allí para ver solo se referirá a la verdad tras un juego dialógico de preguntas y respuestas, tras un proceso dialéctico de investigación que puede, o no, inducirlo a enunciar esa verdad esperada o temida. Ese es el caso del pastor de Citerón quien, después de haber sido interrogado, enuncia esa verdad que dará fin a la tragedia. Ese es también el caso de las historias narradas por Tucídides, que se mantienen presas al relato de los "testigos de vista". Ellas no se limitan a enunciar aquello que los testigos narraron sino que prefieren someter a esas figuras a exámenes e interrogatorios que hacen que su visión del pasado pueda tornarse lo mas rica posible; pues al mismo tiempo en que esos exámenes evidencian y excluyen contradicciones, pueden introducir la duda allí donde las certezas parecían evidentes.

Una transformación semejante caracteriza al saber médico del mismo período. Es entonces que emerge ese arte de curar que se modificará enteramente con las enseñanzas hipocráticas que establecen nuevos códigos y nuevas pautas de comportamiento. Junto a la producción del saber histórico del siglo V a.C., tiene lugar la invención de un saber médico liberado de sujeciones a los postulados metafísicos inoperantes que caracterizaban a la medicina propia de la época arcaica. Los escritos de la colección hipocrática son quienes denuncian esa mutación epistémica. Ciertamente se trata de una reunión, mas o menos arbitraria, de escritos que no pueden pertenecer a una misma persona ni pueden provenir de un mismo lugar, pero que, sin embargo sintetizan un nuevo modo de tematizar el cuerpo y la salud que parece iniciarse con Hipócrates de Cos.

Allí, se pretende romper de manera definitiva con una tradición que hablaba de enfermedades sagradas, designios divinos y destinos inmodificables, ahora la enfermedad pasará a formar parte de la naturaleza y será un proceso en el que es factible interferir para modificarlo. La medicina hipocrática nos hablará de síntomas y no de entidades nosológicas inmutables, e intentará establecer pautas mas o menos eficaces para prevenir mayores consecuencias, y para restaurar el "equilibrio" perdido. Aquí resulta de mayor importancia establecer el pronóstico que enunciar un diagnóstico, y para ello será preciso comprender esos síntomas que configuran la enfermedad, pero también situar a esos signos en la concreción de este paciente y de este tipo peculiar de afección. Será preciso atender a consideraciones sobre la naturaleza del enfermo, a las prescripciones médica y a quien prescribe, pues, este puede sugerir cierto tipo peculiar de temores o de esperanzas.

Para la tradición hipocrática la medicina es considerada un arte, téchne, que a pesar de ser la mas distinguida entre todas, puede resultar al mismo tiempo la menos estimada. Ello se debe a que con frecuencia ese arte es ejercido con desidia e ignorancia, y que, al no estar sujeta a penalidades su único límite lo impone la decisión ética. "La medicina es el único arte que en nuestros estados no está sujeto a ninguna penalidad, excepto la deshonra, pero la deshonra no hiere a quienes se vinculan con ella" (Babini, 1975, p.55). Es así que muchas veces la inexperiencia o la ignorancia se convierten en una "carga maldita" que es fuente de cobardía, que no es otra cosa más que "impotencia y carencia de arte". 
En contrapartida, la única ganancia concreta y efectiva de la que el médico puede beneficiarse es su honra, su fama y el placer de realizar su arte con perfección, cosa que solo puede ser conquistada a base de pronósticos acertados y curaciones eficaces. Lograr esos objetivos puntuales exige, como se afirma en el escrito "Decoro", acompañar al enfermo, visitarlo con frecuencia, interrogarlo sobre sus síntomas, informarlo sobre su estado. Exige ser un hombre prudente y veraz capaz de un diálogo simétrico con el enfermo. Esto se evidencia con claridad en el escrito "Régimen", referido a uno de los ejes articuladores de la medicina griega, donde se hace evidente que "la dietética no era concebida como una obediencia absoluta al saber del otro, ella debía ser por parte del individuo una práctica reflexiva de sí y de su cuerpo" (Foucault, 1985, p.97). Ciertamente se recomienda oír los consejos de aquellos "que saben", de los médicos, pero ese vínculo no es prescriptivo sino que adopta la forma de la "persuasión", pues es en último análisis una cuestión de reflexión y de prudencia que atañe al propio enfermo.

\section{Los griegos y la condición humana}

Esa figura del testigo que es central en el discurso jurídico y en la investigación histórica, puede ser pensada por analogía con el cuerpo enfermo pasible ahora de ser objeto de interrogación y diálogo. Ambos pueden tematizarse como siendo los ejes articuladores que permitieron el ejercicio de esa práctica "cuasi-ritual" que los antiguos griegos llamaron "dialéctica", y que tornó posible la emergencia de algo semejante a la discusión filosófica y a la producción científica. Es que como afirma Giorgio Colli (1977, p.63) "la dialéctica nace en el terreno del agonismo ... cuando el fondo religioso se ha alejado y el impulso cognitivo ya no necesita el estímulo de un desafío del Dios, cuando la porfía entre hombres ya no requiere que estos sean adivinos, entonces aparece un agonismo exclusivamente humano". Queda entablado así un juego donde los hombres se desafían unos a otros a dar respuestas a cuestiones que confesadamente ignoran, a fin de producir en ese diálogo la esperada o temida verdad.

La esfera de discusión y de diálogo, el juego de preguntar y responder, forma parte de ese ámbito de la existencia que los griegos aislaron como siendo el ámbito de "lo propiamente humano". Este se define por un modo de existir entre iguales que exige y supone el uso de esas artes que son la dialéctica y la retórica. Es por ello que Aristóteles añade a la definición de hombre "zoon politicón", una segunda especificación por la que el hombre puede ser pensado como "Zoon Logon ekhón", esto es: ser vivo capaz de discurso. Es que, la polis era ese espacio donde todo debía ser enunciado, allí donde la violencia podía ser excluida hacia el exterior de sus muros. "Para el modo de pensar griego, obligar a las personas por medio de la fuerza, mandar en lugar de persuadir, eran formas pre-políticas para tratar con gente cuya existencia estaba al margen de la polis" (Arendt, 1993, p.40). Ciertamente era eso lo que le permitía a los griegos convivir con formas despóticas de organización como la esclavitud 
o el patriarcado. Coexistían así, espacios donde regía la violencia muda junto a ese espacio dialógico entre iguales que era considerado como la esfera de lo propiamente humano. Es que, los esclavos, los bárbaros y las mujeres eran "aneu logou" (sin logos), claro está que esto no significa que estén "desprovistos de la facultad del discurso, sino de una forma de vida en la que el discurso y solo éste tenían sentido y donde la preocupación primera entre los ciudadanos era hablar entre ellos" (p.44).

Pero será preciso que nos interroguemos respecto de que es lo que posibilita que esas esferas coexistan. Es que una nos habla del ámbito de la necesidad y la otra del espacio de la libertad. Según H. Arendt:

lo que dieron por sentado los filósofos griegos, fuera cual fuera su posición respecto de la polis, es que la libertad se localiza exclusivamente en la esfera politica, que la necesidad es de manera fundamental un fenómeno pre-político ... y que la fuerza y la violencia se justifican en esa esfera porque son los únicos medios para dominar la necesidad y llegar a ser libres. (p.41)

Recordemos que para los griegos la libertad era condición de posibilidad de la "eudaimonía" y que una existencia feliz solo podía ser imaginable para aquellos que no estaban sujetos a las necesidades de la vida o al mandato de los otros. Y esa esfera de la libertad estaba signada por la palabra, por el diálogo entre iguales, un diálogo que no siempre significaba armónica convivencia sino simple exclusión de formas pre-políticas y mudas de violencia.

pertenecer a los iguales significaba la autorización de vivir entre pares, pero la esfera pública, la polis, estaba calada de un espíritu agonal donde todo individuo tenía que distinguirse constantemente de los demás, demostrar, con acciones únicas que era el mejor. Esa esfera estaba reservada a la individualidad pues era el único lugar donde los hombres podían demostrar real e inevitablemente quienes eran. (p.52)

Era en ese ámbito de la libertad y el diálogo agonístico donde cada individuo podía constituirse a si mismo como valiente, o justo, o veraz, y era allí, entre iguales, donde una existencia podía ser modelada. Es que en ese ámbito donde no existían ni gobernantes ni gobernados los ciudadanos podían ser al mismo tiempo testigos e inquisidores, estar allí para ver y contar, pero también para interrogar y juzgar. A todos y a cada uno les tocaba compartir el peso de la administración, la justicia y la defensa, pero también a todos les tocaba interrogar y juzgar. El diálogo que está allí en juego requiere de la presencia de los otros, pero requiere también, y fundamentalmente, que esos otros no sean ni dioses ni esclavos, requiere que podamos salir de la enunciación profética o la aceptación pasiva, precisa que el juego de persuasión que envuelve al diálogo sea jugado por actores libres.

Solo en este marco pudieron emerger esos saberes, ciertamente considerados entonces menores, como son la medicina, el derecho o la historia. Es que ellos suponen el ejercicio de la dialéctica, el arte de la interrogación y el diálogo, y, en todos los casos, ya se trate de la producción de una verdad histórica, o del desvendamiento de una trama jurídica, o de la resolución de un dilema médico, se precisa suponer la existencia 
del otro como un igual: como un testigo capas de logos, de narrar lo ocurrido o como un enfermo capaz de relatar sus afecciones. Lo cierto es que, en ningún caso, ese otro con el que se entabla el diálogo podrá ser considerado como dios o esclavo. Se apelará, en cambio, a la mirada y al decir humano, único capaz de tornar ese juego agonístico en una competencia leal donde no existen de antemano ni vencedores ni vencidos.

\section{A propósito del arte de vivir}

Existe otro punto de intersección entre estos saberes y el ámbito de la ética que excede esa obvia identidad, que arriba señalábamos, entre la metodología que es propia de esos saberes menores y el modo en que se relacionan entre sí los ciudadanos libres. Nos referiremos ahora a los vínculos existentes entre estos saberes y esa preocupación, tan propia de la ética griega, por la dignidad de la existencia, o por el denominado "arte de vivir". En el segundo volumen de La historia de la sexualidad, Michel Foucault (1985) exploró la incidencia del discurso médico hipocrático en el arte de vivir, mostrando que las contribuciones de esa medicina referidas a las dietas o a los ejercicios tendían menos a la cura de enfermedades, que a conseguir ese dominio de sí que era para los griegos un elemento indispensable de la estética de la existencia.

Pero nos referiremos aquí a la "historia" y a su vinculación con la ética griega, dejando de lado precisiones metodológicas e interrogándonos por la operatividad de ese saber para la existencia cotidiana de los ciudadanos. En este punto, Hannah Arendt y Collingwood coincidirán, pues para ambos existe una utilidad adicional del análisis histórico de la época griega que es semejante a la utilidad de la política. Allí se narran existencias ejemplares capaces de instruirnos y de advertirnos, capaces de enseñarnos a "detener voluntariamente las oscilaciones de la propia vida antes de que lleguemos a un punto de peligro" (Collingwood, 1989, p.32). Es una característica inherente a la historia, que su contenido, cualquiera que este sea, solo se revela una vez que ha finalizado, que pasa a formar parte de lo ya ocurrido. En oposición a la fabricación de objetos donde el modelo precede a la fabricación, en el caso de la narración histórica, la inteligibilidad es retrospectiva, aparece solamente al final. Esa marca que es propia de todo pensar histórico se encuentra limitada en los griegos por el excesivo poder concedido a los testigos de vista. La historia estaba para ellos limitada a ese relato, pero eso no implicaba que los testigos conocieran por si mismos la verdad de los hechos. El relato obtenido era del orden del efecto: un resultado del juego dialógico entablado por el narrador; de las preguntas, las sugerencias y las cuestiones que este suscitaba. Tal es así que, como afirma Arendt

lo que el narrador cuenta ha de estar necesariamente oculto para el propio actor, al menos mientras realiza el acto o se halla atrapado en sus consecuencias, ya que para él la significación de su acto no está en la historia que sigue. Aunque las historias son los resultados inevitables de la acción, no es el actor sino el narrador quien capta y hace la historia. (1993, p.215) 
Si nos preguntamos ahora como puede incidir este fenómeno de "falta de predicción del resultado de la historia" en la ética griega, será preciso recordar que la historia es también el relato de los actos que componen una vida. Y que es justamente en ese hecho de poder ser narrada que una existencia se hace pasible de adquirir cierto estilo, cierta integridad moral, cierta belleza. Quizás sea por eso que los griegos creían que "nadie puede llamarse eudeimôn, antes de su muerte" (p.216). Es que ese bienestar que acompaña a ciertos hombres durante toda su vida solo puede ser revelado como propio de una bella existencia cuando ésta ya ha concluido. Y ello porque es entonces, y solo entonces que la vida se hace historia y adquiere así cierta inteligibilidad. Es que, "esa identidad de la persona, aunque revelándose intangible en acto y en el discurso, solo se hace tangible en la historia de la vida del actor; pero como tal únicamente puede conocerse, es decir, agarrarse como palpable entidad después de que haya terminado" (p.216). Después de que haya ingresado en el ámbito de la narración histórica. Solo entonces es posible hablar de una existencia ejemplar, pues es allí que se reconoce y se hace inteligible la existencia del otro. Como afirma Collingwood, la historia posee una utilidad adicional, sirve para enunciar juicios de pronóstico, no demostrables pero si probables, juicios que advierten que eventualmente algo semejante podrá acontecer en nuestras vidas, que nos indican que fuera de todo determinismo el transcurso de los hechos está abierto a modificaciones para las cuales esos relatos pueden venir a auxiliarnos.

Por fin, digamos que si la historia tiene alguna utilidad para la ética, se debe a que ella, al igual que la literatura nos sitúa ante la radical alteridad de la experiencia del otro. Mantenemos con ella un diálogo silencioso que nos obliga a distanciarnos de nuestra experiencia inmediata, nos impone la necesidad de reflexionar sobre el modo de actuar heroico o cobarde, virtuoso o mezquino de esos hombres que en circunstancias precisas debieron elegir su propio destino. A diferencia del mito que no es dialógico sino monológico, la historia nos posiciona ante una evidencia, nuestra existencia no es más que un relato posible que se sitúa en el interior de una trama en la que se entreteje todo ese conjunto de narraciones que hemos conocido y amado (MacIntyre, 1987).

\section{Para concluir}

Esos saberes menores que intentamos aquí caracterizar se oponen frontalmente al pensamiento mítico. Este último hablaba de voluntades divinas que rigen acciones humanas y no de aquello que los hombres efectiva y realmente realizan. El discurso mítico, sea que se trate de un discurso próximo al derecho, a la historia o incluso al propio saber médico, nos habla un idioma de la certeza, donde no hay lugar para dudas o cuestionamientos, pues, ningún hombre tiene el poder de interrogar a los dioses; pero, al mismo tiempo, se trata de un discurso que profiere comandos, que prescribe que es lo que debe y que es lo que no debe ser hecho por los hombres.

Es cierto que ninguno de los tres saberes aquí referidos nos sitúa en el ámbito del "verdadero conocimiento", es cierto que si atendemos a la escala platónica del 
saber, nos mantenemos en el ámbito de la mera opinión. Tanto la historia, como el derecho o el saber médico eran considerados por los griegos como techné, arte mas que episteme, y quizás sea por ello que la verdad aquí no es debelada o contemplada, que ella no produce ese efecto clarificador propio del sol del mundo inteligible, sino que ella es, al contrario, producida casi artesanalmente. Esos saberes pertenecen, igual que la política, al reino de la producción artística, pero dentro de él se sitúan en ese dominio específico que supone el ejercicio de la dialéctica. Es que solo ella permite que sea garantizada la producción de opiniones verdaderas, opiniones que surgen de la confrontación de posiciones y puntos de vista diversos. Como afirma Hannah Arendt:

Cuanto mas numerosos sean los puntos de vista que tengo presentes en mi espíritu, en el momento en que considero una cuestión, y cuanto mejor puedo imaginar de que forma sentiría y pensaría si estuviera en el lugar de los otros, tanto mas fuerte será mi capacidad de pensamiento representativo, y tanto mas válidas mis consideraciones finales - mi opinión. (apud Habermas, 1980, p.117)

Es ese el modo de conocer que caracteriza al pensamiento político griego, así como a esos saberes menores que no podían alcanzar el estatuto de episteme.

Es también techné y opinión el ámbito propio de la ética griega, el dominio específico de esa peculiar creación artística que ya no se refiere a los objetos externos, sino a la propia existencia. Decíamos al inicio de este trabajo que pretendíamos mostrar ese punto de intersección en el que la ética y el orden del saber se encuentran y se refuerzan, centrándonos en el pensamiento griego. Como hemos intentando señalar, ese punto parece situarse en ese juego dialéctico, en ese espacio agonístico donde la palabra y el diálogo son las armas que purgan a los individuos de las supersticiones y los prejuicios; y "los auxilia en ese proceso de pensamiento, como creía Platón, al liberarlos del mal sin necesariamente hacerlos buenos" (Arendt, 1992, p.173). Es por eso que Hannnah Arendt pudo afirmar en "La vida del espíritu" que, "si es que existe algo en el pensar que puede impedir a los hombres que hagan el mal, ese algo deberá ser inherente a la propia actividad del pensar, e independiente del objeto pensado" (p.180). Ese algo, era para los griegos el modelo socrático, dialógico, que abría la posibilidad de instaurar un hablar silencioso del yo consigo mismo. Y, si es posible hablar allí de diálogo y no de monólogo, es porque ese decir supone que esa relación del yo consigo mismo no es de inmediatez, que ella se encuentra mediatizada por la intersubjetividad y la pluralidad que el juego dialógico supone: "aún si evito toda compañía y permanezco aislada al formar una opinión, no estoy simplemente junto a mi misma en la soledad del pensamiento; permanezco en este mundo de interdependencia en el que puedo tornarme representante de todos los demás". Ocurre que "el propio proceso de formación de la opinión es determinado por aquellos en cuyo lugar alguien piensa y usa su propia mente, y la única condición para ese ejercicio de la imaginación es el desinterés, la liberación en relación a nuestros intereses privados" (Habermas, 1980, p.117). No existe posibilidad alguna de convertir al monólogo en diálogo sino es por la convicción de la existencia de esos otros que me informan respecto de mi propia existencia, que establecen una mediación y una distancia respecto de mis mismo capaz 
de hacer de esto que soy un objeto de reflexión, pero también un objeto pasible de ser modelado como lo es una obra de arte.

Ese descubrimiento del otro como un elemento indispensable para la reflexión ética, para la acción política y para la producción de la verdad, no solo se evidencia en el diálogo socrático, sino que también se hace presente allí donde existen esos saberes que nos informan de la existencia de esas vidas ejemplares que poblaron la historia; que nos hablan de justicias e injusticias cometidas; o que, simplemente, nos instruyen acerca de los cuidados que es preciso dirigir a nuestro propio cuerpo si queremos ingresar en el ámbito de la vida activa y escapar de la esclavitud a la que nos somete el dolor y el sufrimiento físico. El orden del saber y la reflexión ética coinciden, en el pensamiento griego, cuando se proponen como meta la ampliación de ese diálogo silencioso que el yo establece consigo mismo, cuando nos indican que, para ello, es preciso suponer la existencia de esas actos, de esos juicios y de esos cuerpos de los que nos hablan la reflexión histórica, el discurso jurídico y el saber médico. Es que esos relatos contribuirán, tanto como la poética, a mediatizar la existencia concreta, haciéndola pasible de convertirse en objeto de reflexión y pensamiento.

Desplacémonos por un instante al renacimiento, y pensemos en esa figura deforme de la literatura shakespeareana que es la de Ricardo III. Lo que ese relato nos narra, es la completa imposibilidad de armonía del yo consigo mismo, la fuerza del monólogo sobre el diálogo, la limitación en el orden de la opinión y del pensamiento. Nos habla, del temor que esa figura despierta en los otros, pero también a si mismo. Allí, se repite y se formula, una y otra vez una misma cuestión, se habla del miedo y de la necesidad de huir, pero ese diálogo temeroso que Gloucester entabla consigo mismo terminará pronto, pues rápidamente conseguirá escapar de su propia compañía. Es que, como afirmará en seguida, "la conciencia (literalmente: conocimiento de si) es apenas una palabra que los cobardes usan. Que fue inventada, antes que nada, para infundir temor a los fuertes" (Arendt, 1993, p.147). Cómo afirmaría Hannah Arendt, al igual que Gloucester, las personas perversas tienden a evitar su propia compañía y lo hacen con un solo objetivo: con el propósito de dejar de pensar. Pues así, no podrán entrar en desacuerdo consigo mismo, no podrán "iniciar ese diálogo que requiere, como apunta Spinoza 'la aquiescencia en si mismo', como parte de esa concordancia que es necesaria para iniciar el proceso dialógico de pensar" (Lafer, 1980, p.97).

El "poder parar para pensar", que era tan valorizado por el pensamiento griego, posee una contracara que es el dogmatismo y la total aceptación de lo ya establecido. La ausencia de pensamiento, de duda y cuestionamiento, es lo que protege a las personas de los peligros del examen, y es por ello que pueden ser aceptadas sin discusión normas o costumbres que demandarían ser cuestionadas. En el ámbito del derecho eso se denomina positivismo jurídico, y en el de la historia dogmatismo. Pero quizás sea en el ámbito del saber médico donde ese límite se torna más patético: pues es allí donde ese sujeto - cuya condición humana era pensada en términos de acción comunicativa - deja de ser agente de diálogo y por ende de reflexión y libertad, para pasar a ser un objeto de cura y un cuerpo a gestionar. Es así que esos saberes, 
desde el momento en que deciden aceptar el principio de "inegabilidad" del punto de partida de las cadenas argumentativas, parecen estar condenados a repetir el gesto de Gloucester. Es allí que la razón dialógica es desplazada en favor de la razón instrumental y que el habla entre iguales se sustituye por una serie de normativas tendientes a inducir en la voluntad de los otros aquello que se considera más eficaz.

La palabra intercambiada entre iguales, donde se excluían las prescripciones divinas y la aceptación pasiva propia de la esclavitud, puede ceder su lugar en favor de un discurso que parece referirse solo a dioses y a esclavos, a aquellos que conciben y a aquellos que ejecutan sin disentir. Ante la demanda de eficacia, los fines determinan una cadena de medios donde el pensar se sustituye por el calcular, donde la duda y el cuestionamiento bien pueden pasar a ser, tal como era la figura de la "conciencia" para Gloucester, un patrimonio de los débiles.

CAPONI, S. N. C. Science and human condition. Trans/Form/Ação (São Paulo), v.19, p.103114, 1996.

- ABSTRACT: It is proposed in this writing to deal whith the theme of the possible links between scientific investigation and ethical reflection. In approaching this question, we propose to backtrack as far as Greek line of thought, and stop at the precise moment when something similar to scientific "truth" first becomes observable, and starts thus to make part of what is "sayable". We are referring to this inaugural instant when historical reflection, medical knowledge, and juridical research have simultaneously appeard. We shall try and demonstrate that, whithin this context, the concern whith truth, far from being alien to ethical reflection, was considered to be the most efficient resource, that which could best contribute in the effort to reach a life worth being lived.

- KEYWORDS: Truth; ethics; historical reflection; medical knowledge; juridical research.

\section{Referencias bibliográficas}

ARENDT, H. La condición humana. Barcelona: Paidós, 1993.

A vida do espírito. Rio de Janeiro: Relume, 1992.

BABINI, J. La ciencia en el siglo de Pericles. Buenos Aires: Centro Editor de America Latina, 1975.

COLLI, G. El nacimiento de la filosofia. Barcelona: Tusquets, 1977.

COLLINGWOOD, R. G. Idea de la historia. México: Fondo de Cultura Económico, 1989.

FOUCAULT, M. La verdad y las formas jurídicas. Barcelona: Gedisa, 1983.

. Histónia da sexualidade II: o uso dos prazeres. Rio de Janeiro: Graal, 1985. p.97.

HABERMAS, J. O conceito de poder em Hannah Arendt. In: Habermas: Sociologia. São Paulo: Ática, 1980.

LAFER, C. Hannah Arendt: pensamento, persuasão e poder. Rio de Janeiro: Paz e Terra, 1980. MAcINTYRE, A. Tras la virtud. Barcelona: Crítica, 1987. 